\title{
Effect of Spraying Calcium Fertilizer on the Fruit Quality of 'summer black' grape
}

\author{
Yan Huang ${ }^{1 \mathrm{a}}$, Jin Wang ${ }^{1 \mathrm{~b}}$, Qiong Zhou ${ }^{2 \mathrm{c}}$ and Xiulan Lv ${ }^{1 \mathrm{~d} *}$ \\ ${ }^{1}$ Institute of Pomology and Olericulture, Sichuan Agricultural University, Chengdu, Sichuan, China \\ ${ }^{2}$ Hanyuan county agricultural bureau, Yaan, Sichuan, China \\ a275477909@qq.com, b251040278@qq.com, “524357446@qq.com, dxllvjj@163.com \\ ${ }^{*}$ Corresponding author. Yan Huang and Jin Wang contributed equally to this work.
}

\begin{abstract}
Keywords: Grapes; Color-changed period; Calcium amino acid; Fruit quality
Abstract: Three-year-old 'summer black' grapes were used for trial material to study the effects of spraying with the different concentrations of calcium fertilizer on grape fruit external quality and intrinsic quality. Fruits were sprayed 1000, 1200, 1400 times amino acids chelate calcium during the fruit color-changed period, and fruits were sprayed clear water for the check. The results showed that the different concentrations of calcium fertilizer improved the external quality and intrinsic quality of 'summer black' grape. Compared with the control, spraying 1000 times amino acids chelate calcium had the most significant effect. The fruit weight of the grape increased by $22.5 \%$, vertical diameter increased by $8.8 \%$, transverse diameter increased by $10.8 \%$, the fruit firmness increased by $35.7 \%$, the content of the titratable acid decreased by $23.2 \%$, the content of soluble sugar increased by $38.7 \%$. The results of this experiment provided some guidance for supplementing calcium and improving fruit quality in grape production.
\end{abstract}

\section{Introduction}

Grape was a kind of calcium-loving fruit, the demand for calcium was much higher than apple, pear, citrus and so on. In recent years, people used N, P, K fertilizer more seriously on the grape production of fertilizer, while ignoring the calcium fertilizer application, causing the grapes lack calcium, water loss, fruit softening, threshing, browning and decay, disease, which had serious impact on storage and sales. The nutritional status of calcium in fruits was closely related to the fruit quality [1]. Many studies had shown that calcium treatment before harvest could effectively improve the fruit quality. Calcium was one of the essential mineral nutrients in fruit trees and had important physiological function in fruit cells. Calcium could maintain cell wall structure [2], maintain fruit firmness, reduce decay during storage, and control physiological diseases of fruit trees [3-6].

$\mathrm{Ca}^{2+}$, as the second messenger of information transmission inside and outside cells, could regulate many physiological and biochemical processes of fruit growth and the activities of important enzymes in cells. Because the root absorption of calcium relied mainly on the phloem in fruit, the absorption of calcium in the early stage of the growth was given priority to, in the later growth stage, because calcium oxalate in fruit stalk blocked phloem, causing that the fruit of calcitonin accumulation was difficult, with the enlargement of the fruit, fruit calcium apparently declined, therefore, during the development of grape calcium had certain significance. Because calcium was difficult to move in plant phloem [7], less calcium was transported to fruit. At present, it had become one of the effective ways to increase the calcium content of fruits by spraying calcium on the fruit surface [8-9].In order to solve the problem of lack of calcium in grape fruits such as serious disease, quality loss and so on, calcium fertilizer could be applied to fruits before harvest. The grape clusters were sprayed different concentration amino acids chelate calcium in this experiment, exploring its influence on 'summer black' grape fruit quality, thus providing certain reference basis for quality improvement for grape production practice. 


\section{Materials and Methods}

Materials. Three-year-old 'summer black' grapes were used in this study. Grapes grown robustly, having the same management and without plant diseases and insect pests. The experiment site is the modern agricultural research and development base of Sichuan Agricultural University. The soil is sandy loam soil and the plant spacing is $1.5 \mathrm{~m} \times 3.0 \mathrm{~m}$.

Experimental Design. This experiment had three different concentrations of calcium fertilizer, and the concentration gradient was set as 1000, 1200 and 1400 times respectively. Spraying water was set as a control (CK). Amino acids chelate calcium was sprayed twice. The spraying time was during the fruit color-changed period (30 days and 50 days after flowering).A total of three treatments and one control were set up in the experiment, and a random group was arranged. Nine grapes were set for each treatment. When the fruit was matured (July 2017), samples are taken for quality determination. Single panicle weight and single grain weight were determined. The vertical and transverse diameters of fruit, the fruit hardness, TSS, soluble sugar content, and titratable acid [10-11].

Statistical Analyses. Data were analyzed using Excel 2010 and SPSS 13.0 statistical software (IBM, Chicago, IL, USA).

\section{Results}

Effects of different concentration of amino acids chelate calcium on external quality of 'summer black' grape. Compared with the control, spraying 1000 times amino acids chelate calcium on 'summer black' grape fruit during the fruit color-changed period not only increased weight of grape, but also had significant effects on vertical diameter and transverse diameter (Table 1). All treatments increased the fruit firmness of 'summer black' grape. It increased by $30.8 \%$, $27.7 \%, 35.7 \%$ respectively. The result showed that the application of calcium amino acid had a good effect on the increase of fruit firmness.

Table 1 Effects of different concentration of amino acids chelate calcium on external quality of 'summer black' grape

\begin{tabular}{|c|c|c|c|c|c|}
\hline $\begin{array}{c}\text { Calcium fertilizer } \\
\text { concentrations }\end{array}$ & $\begin{array}{c}\text { Fruit weight } \\
(\mathrm{g})\end{array}$ & $\begin{array}{c}\text { Vertical diameter } \\
(\mathrm{mm})\end{array}$ & $\begin{array}{c}\text { Transverse } \\
\text { diameter } \\
(\mathrm{mm})\end{array}$ & $\begin{array}{c}\text { Fruit } \\
\text { shape } \\
\text { index }\end{array}$ & $\begin{array}{c}\text { Fruit firmness } \\
\left(\mathrm{kg} \cdot \mathrm{cm}^{-2}\right)\end{array}$ \\
\hline 0 & $5.130 \pm 0.609 \mathrm{~b}$ & $19.324 \pm 1.047 \mathrm{~b}$ & $21.451 \pm 1.746 \mathrm{~b}$ & 1.110 & $0.81 \pm 0.148 \mathrm{~b}$ \\
\hline 1400 times & $5.872 \pm 0.58 \mathrm{ab}$ & $20.171 \pm 0.801 \mathrm{ab}$ & $22.124 \pm 1.171 \mathrm{~b}$ & 1.097 & $1.17 \pm 0.278 \mathrm{a}$ \\
\hline 1200 times & $5.585 \pm 0.344 \mathrm{ab}$ & $19.857 \pm 1.209 \mathrm{~b}$ & $22.068 \pm 1.475 \mathrm{~b}$ & 1.111 & $1.12 \pm 0.203 \mathrm{a}$ \\
\hline 1000 times & $6.619 \pm 0.843 \mathrm{a}$ & $21.200 \pm 1.379 \mathrm{a}$ & $24.052 \pm 1.754 \mathrm{a}$ & 1.135 & $1.26 \pm 0.181 \mathrm{a}$ \\
\hline
\end{tabular}

Note: Different lowercase letters marked with the same column data indicate a significant difference $(\mathrm{P}<0.05)$, the same as the following table.

Effects of different concentration of amino acids chelate calcium on intrinsic quality of 'summer black' grape. Compared with the control, three treatments all increased TSS of 'summer black' grape (Table 2).While spraying 1200, 1400 times amino acids chelate calcium on 'summer black' grape fruit had significant effects on TSS during the fruit color-changed period, increasing by $7.6 \%, 10.9 \%$ respectively. Moreover all treatments decreased titratable acid content of 'summer black' grape and had significant effects on titratable acid content of 'summer black' grape. It decreased by $19.2 \%, 13.8 \%, 23.2 \%$ respectively. Compared with the control, spraying 1000 times amino acids chelate calcium on 'summer black' grape fruit during the fruit color-changed period had significant effects on soluble sugar content of 'summer black' grape, 
increasing by $38.7 \%$.Thus, spraying 1000 times calcium amino acid could improve intrinsic quality of 'summer black' grape.

Table 2 Effects of different concentration of calcium nitrate solution on intrinsic quality of 'summer black' grape.

\begin{tabular}{|c|c|c|c|c|}
\hline $\begin{array}{c}\text { Calcium fertilizer } \\
\text { concentrations }\end{array}$ & TSS $(\%)$ & $\begin{array}{c}\text { Titratable acid } \\
\text { content }(\%)\end{array}$ & $\begin{array}{c}\text { Tss-acid } \\
\text { ratio }\end{array}$ & $\begin{array}{c}\text { Soluble sugar } \\
\text { content }(\%)\end{array}$ \\
\hline 0 & $17.85 \pm 1.236 \mathrm{c}$ & $0.522 \pm 0.018 \mathrm{a}$ & 34.195 & $8.982 \pm 0.661 \mathrm{~b}$ \\
\hline 1400 times & $20.04 \pm 1.204 \mathrm{a}$ & $0.422 \pm 0.008 \mathrm{~cd}$ & 47.488 & $10.719 \pm 1.817 \mathrm{ab}$ \\
\hline 1200 times & $19.31 \pm 1.112 \mathrm{ab}$ & $0.45 \pm 0.007 \mathrm{bc}$ & 42.911 & $13.342 \pm 0.185 \mathrm{ab}$ \\
\hline 1000 times & $18.75 \pm 0.771 \mathrm{bc}$ & $0.401 \pm 0.004 \mathrm{~d}$ & 46.758 & $14.644 \pm 2.438 \mathrm{a}$ \\
\hline
\end{tabular}

\section{Discussion}

Calcium was a necessary nutrient element for plant growth. The effect of soil application of calcium fertilizer was greatly influenced by orchard soil, root system and other factors. Calcium had little mobility in trees and was difficult to be reused. Some fruits, such as grapes, apples, peaches and mangoes, were prone to calcium deficiency physiological diseases. Therefore, injecting calcium to the fruit surface in the fruit production could increase the amount of calcium. M. Li [12] believed that there were many problems after the spraying of some macromolecular calcium ions. For example, the spraying of calcium chloride could easily lead to the closure of the stomata on the leaf surface and burn the leaf at high temperature. Amino acids chelate calcium molecules was small, absorbed easily, could also improve fruit sitting rate, promote flower bud formation.

The effect of calcium content on the sugar and acid quality of fruit had been concerned by many scholars, but there were different reports. The test results showed that the calcium could increase soluble sugar content, decreased titratable acid content, and improved the effect of fruit firmness. The results were similar to the research of Liu xinming [13] and Su xuede [14], and Fallahi [15] did not match the research reports on the marshal apples.

In this study, the result showed that using amino acids chelate calcium on 'summer black' grape fruit during the fruit color-changed period could improve external quality and intrinsic quality of 'summer black' grape. This result was consistent with the research of $\mathrm{Xu}$ xinlin, Wen xu, Guan junfeng, Xie peirong, Huang hongxin [16-19].It indicated that calcium fertilizer had a great effect on improving quality of a lot of fruits.

\section{Conclusions}

The results showed that spraying 1000 times amino acids chelate calcium during the fruit color-changed period could increase fruit weight, vertical diameter, transverse diameter and fruit firmness of 'summer black' grape, thus improving enteral quality. On the other hand, 1000 times amino acids chelate calcium during the fruit color-changed period increased soluble sugar content and decreased titratable acid content of 'summer black' grape. It had significant effects on improving intrinsic quality. The results had certain reference value to provide exogenous calcium and improve the quality of grape fruit.

\section{Acknowledgements}

This work was financially supported by the Viticulture Technology Research Position of the Sichuan Fruit Innovation Team of the National Modern Agricultural Industry Technology System. 


\section{References}

[1] J.F. Guan, MaxSaure: Science press, 2005

[2] X.M. Huang, H.B. Huang, H.C. Wang:Scientia Horticulturae Vol. 3 (2005), p. 249

[3] C. Alcaraz-Lopez, M. Botia, C.F. Alcaraz: Journal of Plant Physiology Vol.160(2003), p. 1441

[4] Y.H. Che, B.Z. Li, Y.G. Wang: Journal of northwestern botany Vol. 25 (2005),p. 803

[5] C. Chervin, D. Lavigne, P. Westercamp: Postharvest Biology \& Technology Vol. 54(2009), p. 115

[6] A. Ciccarese, A.M. Stellacci, G. Gentilesco: Postharvest Biology \& Technology Vol. 75(2013), p. 135

[7] J.L. Lu: Beijing: China agricultural university press(2003),p 66

[8] W. Zhou,S.T. Shu, B.Lin:Soil fertilizers Vol 6(2000),p 25

[9] W.H. Hua, R.Y.Wang: Fruit science Vol. 15(1998),p 20

[10] B. Z. Bai: Plant Physiology (China Agriculture Press, Beijing, China 2003)

[11] M.M. Cao, X.J. Bai, Y.R. Bai, Y.R. Li, T.L. Xie, R.D. Wen, J.B. Liu: Guangdong Agricultural Sciences Issue. 2 (2010), p. 113

[12] M.Li,E.M. Li,Z. Li: Jiangsu agricultural science Vol. 41 (2013), p. 180

[13] X.L. Xu, Z.J. Wang, Y.H. Guo: Chinese and foreign grape and wine Vol. 4 (2002), p. 40

[14] X.D. Su, J.S. Yang:Journal of gansu agricultural university Vol. 44(2009), p.73

[15] Fallahi: Tree Fruit Productions Vol.1(1996), p. 15

[16] X. Wen, Y.L Wang: Journal of xinjiang agricultural university Vol.6 (2011), p. 482

[17] J.F. Guan,L.B. Zhang,F.M. Yu: Journal of hebei agricultural university Vol.22 (1999), p. 43

[18] P.R. Xie,X.H. Ma,J.Y. Ouyang: China agricultural science bulletin Vol.25 (2009), p. 82

[19] H.X. Huang, C.P. Yang,L.J. Liu: Hubei agricultural science Vol.51(2012),p. 2546 